\title{
Pengimplementasian CRM Pada Pembangunan E-Commerce untuk Usaha Mikro Kecil Menengah (Studi Kasus: Dolanan Puzzle)
}

\author{
Handaru Eri Pramudiya ${ }^{1}$, Yonathan Dri Handarkho ${ }^{2}$, Flourensia Sapty Rahayu ${ }^{3}$ \\ 1,2,3 Program Studi Teknik Informatika, Fakultas Teknologi Industri, Universitas Atma Jaya Yogyakarta \\ Jl. Babarsari 43, Yogyakarta 55281 \\ E-mail: ${ }^{1}$ handaru.eri@gmail.com, ${ }^{2}$ yonathan_dh@mail.uajy.ac.id, ${ }^{3}$ sapty@mail.uajy.ac.id
}

Masuk: 8 April 2015; Direvisi: 20 April 2015; Diterima: 23 April 2015

\begin{abstract}
Using information technology to gain competitive advantage is no longer dominated by big enterprises. Other business units such as MSMEs (Micro Small Medium Enterprises) also start to adopt information technology into their business. E-Commerce is an example of technology that can be used easily to selling and marketing a product. Marketing in E-Commerce can still be improved by integrating CRM (Customer Relationship Management) concept into it. Dolanan Puzzle is an example of MSME focusing on tools of educational games in Yogyakarta. Currently Dolanan Puzzle still uses manual method to run their business. It limits the market of Dolanan Puzzle and it is hard to reach their customers. Integration of E-Commerce with CRM can be a solution for Dolanan Puzzle to develop their business. Using E-Commerce as an online store enables customers to reach Dolanan Puzzle easily. Further more, marketing product from Dolanan Puzzle can also be improved by using implementation of CRM in E-Commerce.

Keywords: CRM, E-Commerce, Marketing, Customer, MSME
\end{abstract}

\begin{abstract}
Abstrak. Tren pemanfaatan teknologi informasi untuk meingkatkan keunggulan kompetitif tidak lagi di dominasi oleh usaha berskala besar saja. Unit usaha seperti UMKM (Usaha Mikro Kecil Menengah) juga secara bertahap mulai mengadopsi teknologi informasi. ECommerce merupakan contoh teknologi yang tepat untuk diterapkan pada UMKM dikarenakan dapat menjadi wadah berjualan dan promosi secara online. Pemasaran di dalam E-Commerce pun dapat ditingkatkan dengan penerapan CRM (Customer Relationship Management). Dolanan Puzzle adalah contoh UMKM produsen Alat Permainan Edukatif di Yogyakarta. Saat ini Dolanan Puzzle belum memanfaatkan teknologi informasi dalam bisnisnya. Hal itu membuat pemasaran dari Dolanan Puzzle tersebut sangat terbatas dan hanya sedikit masyarakat yang mengetahui tentang Dolanan Puzzle. Pembuatan E-Commerce dengan pengimplementasian CRM di dalamnya dapat menjadi jalan keluar untuk Dolanan Puzzle dalam mengembangkan usahanya. Adanya ECommerce sebagai toko online Dolanan Puzzle memudahkan pelanggan dalam mencarinya. Promosi dari Dolanan Puzzle pun dapat ditingkatkan dengan penerapan CRM pada E-Commerce Dolanan Puzzle tersebut.
\end{abstract}

Kata Kunci: CRM, E-Commerce, promosi, pelanggan, UMKM

\section{Pendahuluan}

Pemanfaatan teknologi informasi sebagai salah satu faktor sukses sebuah unit usaha tidak lagi didominasi oleh perusahaan besar saja. Banyak unit usaha pada skala Usaha Mikro Kecil Menengah (UMKM) yang mulai memanfaatkan teknologi informasi untuk menunjang proses bisnis mereka. Hal tersebut dikarenakan teknologi informasi merupakan salah satu instrumen yang efektif agar UMKM tetap memiliki keunggulan kompetitif ditengah persaingan usaha yang begitu ketat (Stale dan Majors, 2010). Melalui pemanfaatan teknologi informasi yang tepat sasaran, keterbatasan keterbatasan yang dimiliki oleh UMKM dapat teratasi dan tertutupi.

Dolanan Puzzle merupakan salah satu contoh UMKM di Yogyakarta yang masih memiliki hambatan dalam menjalankan usahanya terutama dalam bidang promosi. Dolanan Puzzle adalah salah satu UMKM yang memproduksi Alat Permainan Edukatif (APE). APE adalah alat permainan yang sengaja dirancang khusus untuk kepentingan pendidikan (Tedjasaputra, 2001). APE merupakan alat yang dapat diserap oleh mata dan telinga dengan tujuan membantu guru agar proses belajar mengajar siswa lebih efektif dan efisien (Sudjana, 2004). Proses pemasaran yang selama ini dilakukan oleh 
Dolanan Puzzle hanya melalui mulut ke mulut. Aktifitas promosi yang masih terbatas dan ditambah dengan tidak tersedianya toko secara fisik, membuat keberadaan Dolanan Puzzle menjadi kurang "terlihat" di masyarakat. Hal tersebut menyebabkan konsumen yang hendak mencari alat permainan edukatif di Yogyakarta, sering kali mengalami kesulitan dikarenakan terbatasnya akses ke produsen alat permainan edukatif tersebut. Mengacu dari hal tersebut, pemanfaatan teknologi informasi dapat menjadi solusi bagi UMKM Dolanan Puzzle untuk meningkatkan keunggulan kompetitif unit usaha tersebut.

E-commerce adalah salah bentuk perwujudan dari penggunaan teknologi informasi yang bisa dimanfaatkan untuk membantu Dolanan Puzzle dalam meningkatkan keunggulan kompetitifnya. Melalui berbagai kelebihan yang dimilikinya, e-commerce dapat menjadi sebuah media promosi yang sangat efektif bagi UMKM yang sedang berkembang (McMaster, dkk., 2004). Melalui e-commerce, banyak UMKM yang bisa memperoleh keuntungan strategis seperti terintegrasinya proses bisnis dari sisi internal dan eksternal, pertumbuhan pasar yang semakin luas, dan meningkatnya relasi dengan konsumen (Poorangi, dkk., 2013). Berkaca dari kebutuhan tersebut, pada penelitian ini akan dibangun sebuah aplikasi e-commerce bernama EDOLPUZ (E-commerce Dolanan Puzzle) yang diperuntukan bagi Dolanan Puzzle. Aplikasi ini ditujukan selain untuk menangani proses transaksi yang terjadi didalam UMKM tersebut, juga akan memiliki beberapa fitur yang merupakan perwujudan dari konsep CRM (Customer Relationship Management) sebagai salah satu media promosi dari UMKM ini. Konsep CRM sendiri dipahami sebagai sebuah pendekatan manajemen berbasis konsumen dengan memanfaatkan sistem informasi sebagai penyedia informasi untuk mendukung proses operasional, analisis dan kolaborasi dalam rangka meningkatkan retensi dari pelanggan (Mishra, 2009). Pada penelitian ini, konsep CRM diwujudkan melalui tersedianya fitur pengelompokkan pelanggan dan penerapan Market Basket Analysis yang ditanamkan pada aplikasi EDOLPUZ yang dibangun pada penelitian ini. Dengan dibangunnya sebuah e-commerce yang menerapkan konsep CRM tersebut, diharapkan selain memudahkan pelanggan untuk berinteraksi dengan Dolanan Puzzle melalui sebuah toko online, UMKM ini juga mampu menjaga dan mempertahankan relasi dengan pelanggan sehingga promosi dan pemasaran produk dari Dolanan Puzzle akan menjadi lebih maksimal.

\section{Landasan Teori}

\subsection{Pemanfaatan Teknologi Informasi pada UMKM}

Di era teknologi informasi yang semakin terbuka ini, penerapan teknologi informasi dan komunikasi oleh usaha kecil menengah dalam menunjang proses bisnisnya sudah menjadi sebuah kebutuhan. Terdapat beberapa penelitian yang menunjukkan hal tersebut. Dalam penelitian terhadap usaha kecil menengah (UKM) di Malaysia (Hashim, 2012), ditemukan sebanyak 48.8\% pelaku usaha kecil menengah di Malaysia sudah menerapkan sistem informasi untuk menunjang proses bisnisnya. Dengan memanfaatkan teknologi informasi untuk mengelola kinerja usahanya, UKM di Malaysia mampu untuk meningkatkan keunggulan kompetitif mereka dalam menghadapi persaingan usaha yang semakin ketat. Untuk kondisi di Indonesia sendiri, saat ini telah banyak UMKM yang mulai memanfaatkan teknologi informasi berupa e-commerce sebagai salah satu bagian rencana pengembangan usaha mereka. Walaupun pemanfaatan teknologi informasi bukanlah sebuah hal yang mudah dan memiliki tantangan terutama dari sisi sumber daya manusia, akan tetapi dengan memahami keuntungan dan mempelajari tantangan yang ada, pemanfaatan teknologi informasi sangat berpotensi membantu memberdayakan UMKM di indonesia menjadi lebih baik (Govindaraju, 2011). Mengacu dari hal tersebut, maka penting bagi pelaku usaha yang mengadopsi teknologi informasi untuk mendukung proses tersebut dengan maksimal dan bersinergi dikarenakan proses adopsi teknologi informasi akan memberikan dampak perubahan terhadap strategi dari unit usaha secara menyeluruh (Ghobakhloo, dkk., 2012).

\subsection{Penerapan CRM pada UMKM}

Terdapat beberapa penelitian yang menunjukkan bagaimana konsep CRM dapat diimplementasikan pada usaha kecil untuk membantu meningkatkan dan mendorong kesuksesan sebuah unit usaha. Garcia, dkk. (2012) menawarkan sebuah kerangka kerja penerapan CRM berdasarkan studi kasus pada UMKM di salah satu negara berkembang di Amerika Latin yaitu Meksiko. Dalam kerangka kerja tersebut, Garcia, dkk. menawarkan sebuah arsitektur CRM untuk 
UMKM yang terbagi dalam dua bagian yaitu operational CRM dan analytical CRM seperti di tunjukkan pada Gambar 1.

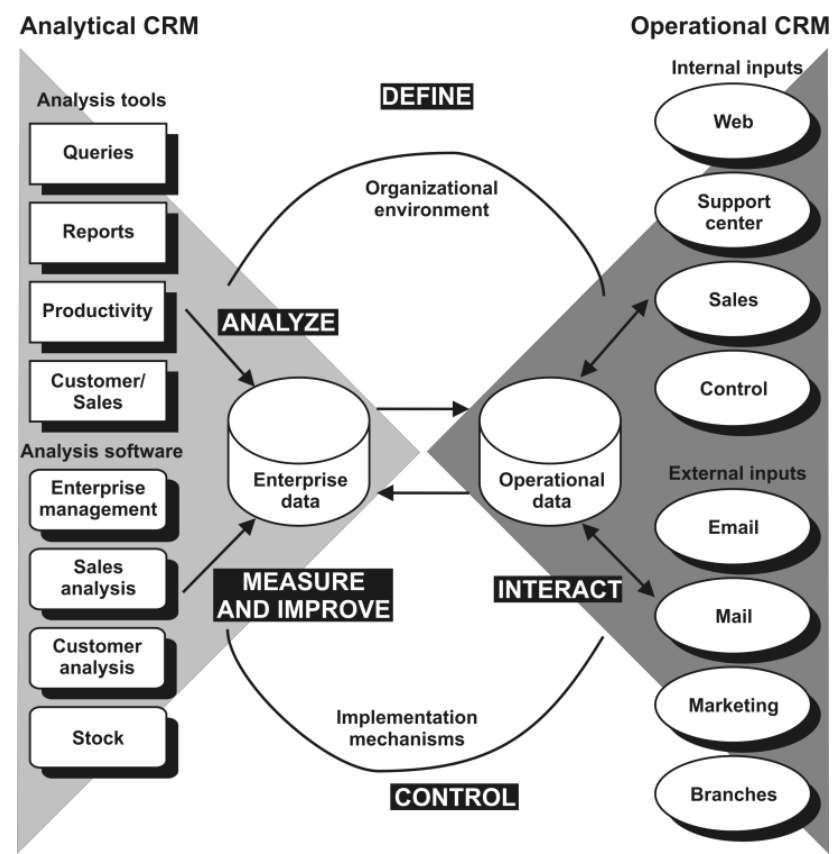

Gambar 1. Arsitektur CRM pada Usaha Kecil Menengah (Garcia, dkk., 2012)

Pengimplementasian CRM pada pembangunan e-commerce pada penelitian ini akan mengadopsi dari arsitektur pada Gambar 1 tersebut. Pada e-commerce yang dibangun pada penelitian ini akan menyediakan dua bagian dari arsitektur CRM pada Gambar 1 yaitu Operational CRM dalam bentuk website yang memiliki fitur sebagai berikut: (1) mengijinkan kosumen untuk melihat berbagai produk dari Dolanan Puzzle dan melakukan transaksi disana, (2) Menyediakan fitur bagi pihak Dolanan Puzzle untuk berinteraksi dengan pelanggannya melalui $e$-mail sebagai sarana promosi dan komunikasi. Selanjutnya untuk bagian kedua adalah Analytical CRM. Pada e-commerce yang dibangun ini, bagian Analytical CRM diwujudkan dalam bentuk: (1) Laporan bagi pihak Dolanan Puzzle yang berisi rangkuman transaksi yang terjadi pada periode tertentu. (2) Penerapan metode Market Basket Analysis kepada konsumen berdasarkan kebiasan membeli konsumen.

\subsection{Metode Market Basket Analysis}

Salah satu metode Analytical CRM yang di terapkan untuk mereferensikan barang guna meningkatkan pemasaran di dalam E-Commerce Dolanan Puzzle ialah metode Market Basket Analysis. Metode Market Basket Analysis merupakan salah satu komponen penting dari proses analisis data pada CRM yang paling sering digunakan dalam dunia pemasaran (Svetina, 2005). Tujuan dari penggunaan metode ini adalah untuk menentukan produk-produk apa saja yang paling sering dibeli atau digunakan sekaligus oleh para konsumen. Dalam prosesnya, Market Basket Analaysis akan menganalisis kebiasaan membeli (buying habits) dari konsumen dengan menemukan asosiasi antar produk-produk yang berbeda yang diletakkan konsumen dalam keranjang belanja (shopping basket). Market Basket Analysis sendiri merupakan implementasi dari Association Rules.

\subsubsection{Metode Dasar Association Rule}

Menurut Nurcahyo (2013), metodologi dasar analisis asosiasi terbagi menjadi dua tahapan yaitu: (1) Analisa pola frekuensi tinggi. Pada tahapan pertama akan dicari kombinasi dari barang A dan B yang memenuhi syarat minimum dari nilai support dalam basis data, dengan rumus pada persamaan 1. (2) Pembentukan aturan asosiatif. Selanjutnya setelah nilai support pada Persamaan 1 ditemukan, pada tahapan kedua akan dicari aturan asosiatif yang memenuhi syarat minimum untuk nilai confidence dari aturan asosiatif $\mathrm{A} \rightarrow \mathrm{B}$ menggunakan rumus pada persamaan 2. Dengan 
Support $(A \cap B)=$ jumlah transaksi mengandung $\mathrm{A}$ dan $\mathrm{B}$ dan $P(\mathrm{~A})=$ jumlah transaksi mengandung $\mathrm{A}$.

$$
\begin{aligned}
& \text { Support }=P(A \cap B)=\frac{\text { jumlah transaksi yang memuat } A \text { dan } B}{\text { total jumlah transaksi }} \\
& \text { Confidence }=P\left(\frac{B}{A}\right)=\frac{P(A \cap B)}{P(A)}
\end{aligned}
$$

\subsubsection{Algoritma Apriori}

Apriori adalah salah satu algoritma yang sudah sangat dikenal dalam melakukan pencarian frequent itemset dengan association rule. Sesuai dengan namanya, algoritma ini menggunakan pengetahuan mengenai frequent itemset yang telah diketahui sebelumnya, untuk memproses informasi selanjutnya. Algoritma ini digunakan untuk mengelompokkan barang barang yang ada di dalam keranjang belanja (Market Basket) untuk dianalisa menggunakan metode association rule.

\section{Analisis dan Perancangan Sistem}

\subsection{Perspektif Produk}

EDOLPUZ (E-commerce Dolanan Puzzle) merupakan sebuah perangkat lunak berbasis web yang dibangun untuk Dolanan Puzzle sebagai sebuah etalase online yang bertujuan untuk membantu memaksimalkan penjualan dan memudahkan pelanggan dalam menjangkau Dolanan Puzzle. Sistem ini juga dapat merekomendasikan kepada pelanggan mengenai barang apa saja yang sering dibeli oleh pelanggan yang lain berdasarkan sebuah produk. Secara umum alur transaksi yang terjadi pada EDOLUZ ditunjukan pada flowchart pada Gambar 2.

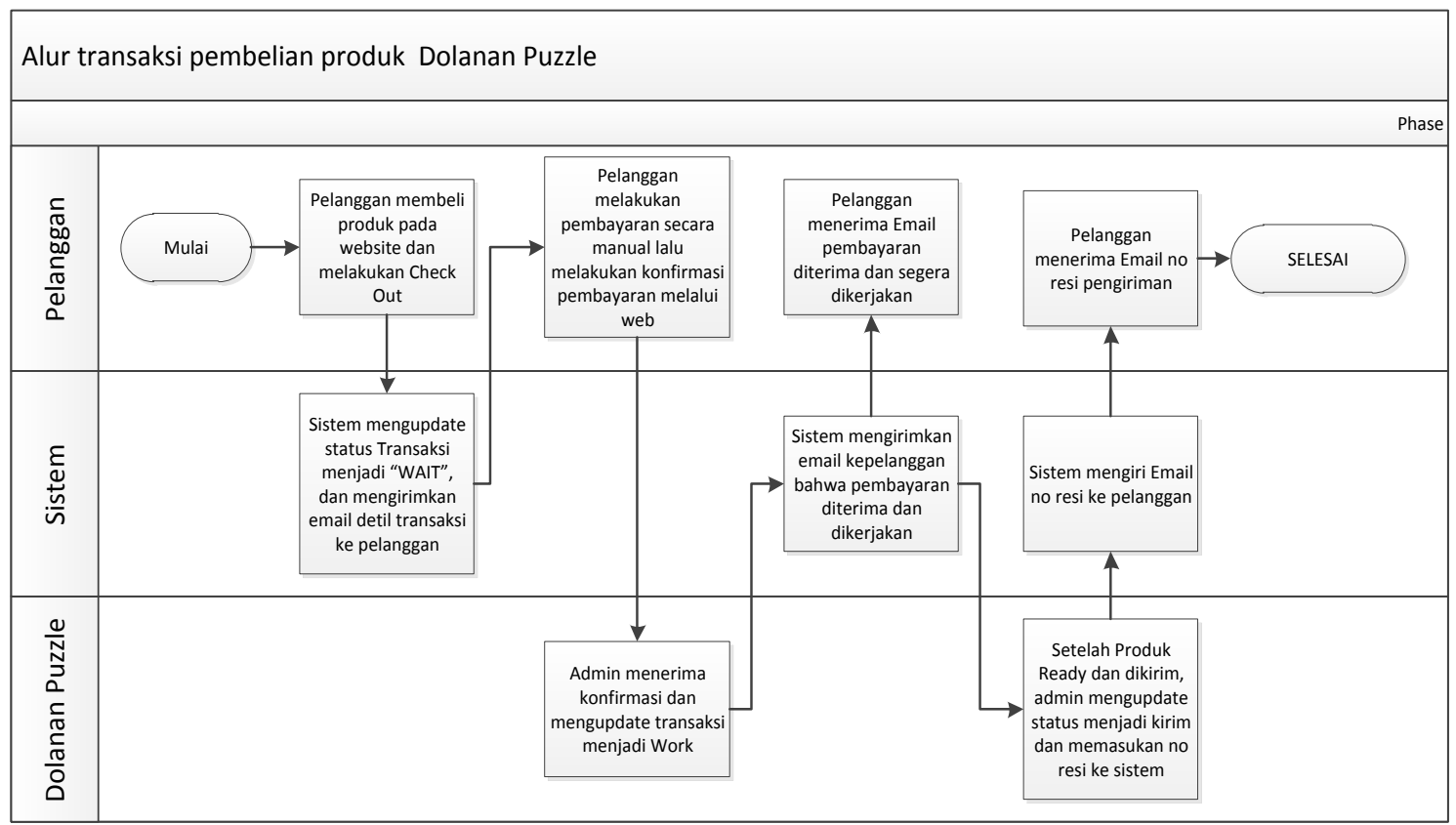

Gambar 2. Basic Flow Alur transaksi

\subsection{Use case Diagram}

Aktifitas pada aplikasi EDOLPUZ ditunjukan melalui diagram use case pada Gambar 3. Terdapat tiga buah aktor pada aplikasi ini yaitu konsumen, pihak admin dan sistem EDOLPUZ sendiri. Pada aplikasi ini, pihak konsumen diijinkan untuk bisa melihat, memilih dan membeli barang dari Dolanan Puzzle secara online. Selanjutnya pihak admin diijinkan untuk mengelola setiap data barang, data transaksi, data pengguna dan data testimoni barang. Sedangkan sistem EDOLPUZ nantinya seacara otomatis akan mengelola pengiriman e-mail ke pelanggan dan mengelola penerapan dari metode Market Basket Analaysis dalam mempromosikan produk dari Dolanan Puzzle. 


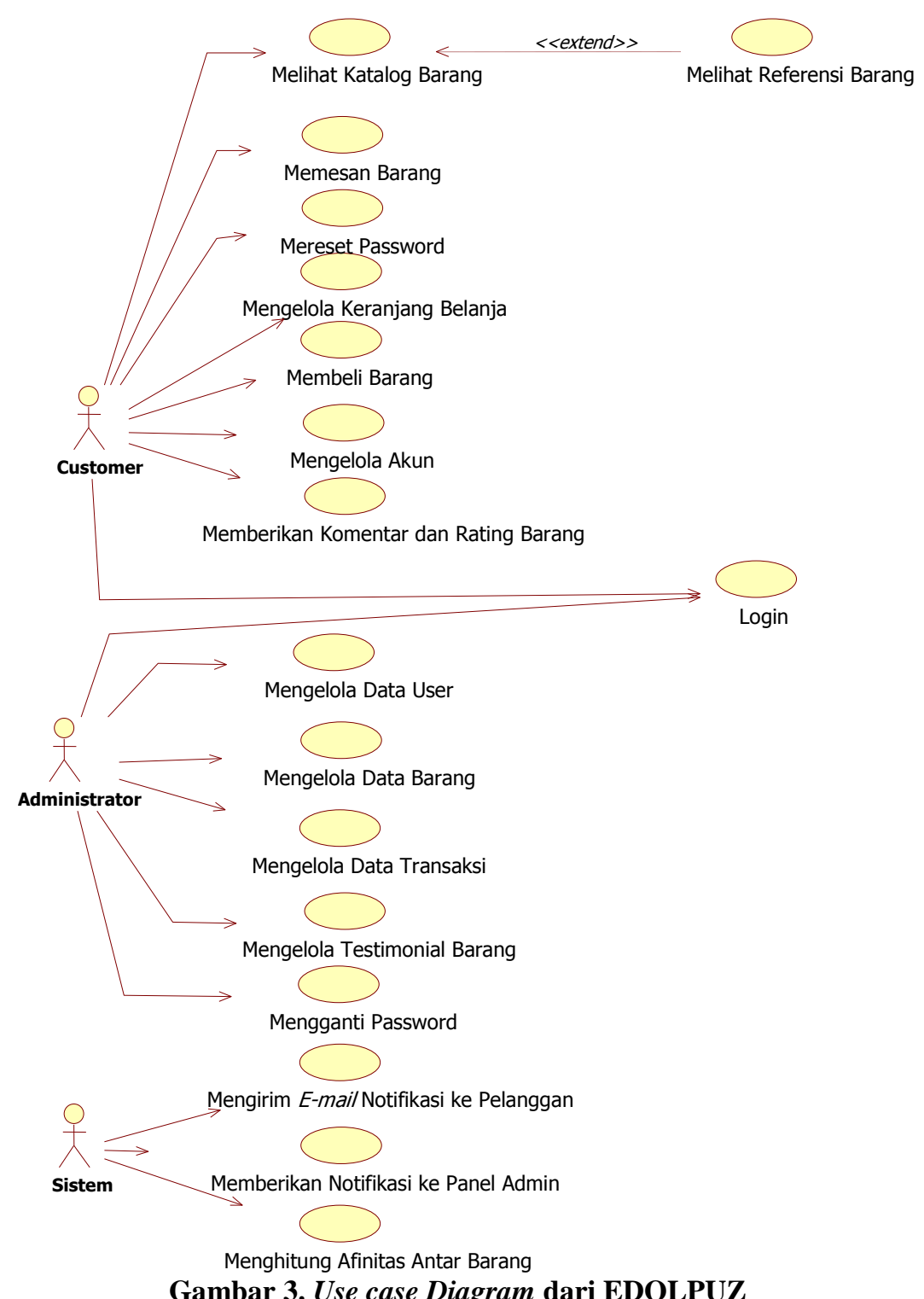

\section{Implementasi dan Pengujian Sistem}

Seperti sudah dijelaskan pada bagian landasan teori, implementasi CRM pada sistem EDOLPUZ dikembangkan berdasarkan kerangka kerja CRM dari Garcia dkk (2012). Pada $e$-commerce yang dibangun pada penelitian ini, menyediakan dua lapisan yaitu Operational CRM dalam bentuk website yang memiliki fitur sebagai berikut: (1) mengijinkan konsumen untuk melihat berbagai produk dari Dolanan Puzzle dan melakukan transaksi disana, (2) Menyediakan fitur bagi pihak Dolanan Puzzle untuk berinteraksi dengan pelanggannya melalui e-mail sebagai sarana promosi dan komunikasi. Selanjutnya untuk lapisan kedua adalah Analytical CRM. Pada e-commerce yang dibangun ini, layar Analytical CRM diwujudkan dalam bentuk: (1) Laporan bagi pihak Dolanan Puzzle yang berisi rangkuman transaksi yang terjadi pada periode tertentu. (2) Penerapan metode Market Basket Analysis kepada konsumen berdasarkan kebiasan membeli konsumen.

\subsection{Implementasi Operational CRM}

Tampilan antarmuka pada Gambar 4 dan Gambar 5 merupakan perwujudan dari lapisan operational CRM yang mengijinkan pelanggan melakukan eksplorasi terhadap produk dari Dolanan Puzzle, memberikan komentar dan juga melakukan transaksi pembelian. Pada Gambar 4 ditunjukkan hasil implementasi untuk tampilan katalog barang yang akan dijumpai oleh 
pelanggan dari Dolanan Puzzle. Pada tab pane pada sisi kiri berisikan jenis jenis produk dari Dolanan Puzzle yang ditawarkan kepada konsumen. Combo box "urutkan berdasarkan", berguna untuk mengurutkan tampilan pada katalog barang berdasarkan nama, harga termurah, atau harga yang paling mahal. Setiap item pada halaman web ini memiliki tombol Add To Cart yang digunakan untuk menambahkan barang tersebut ke dalam shopping cart.

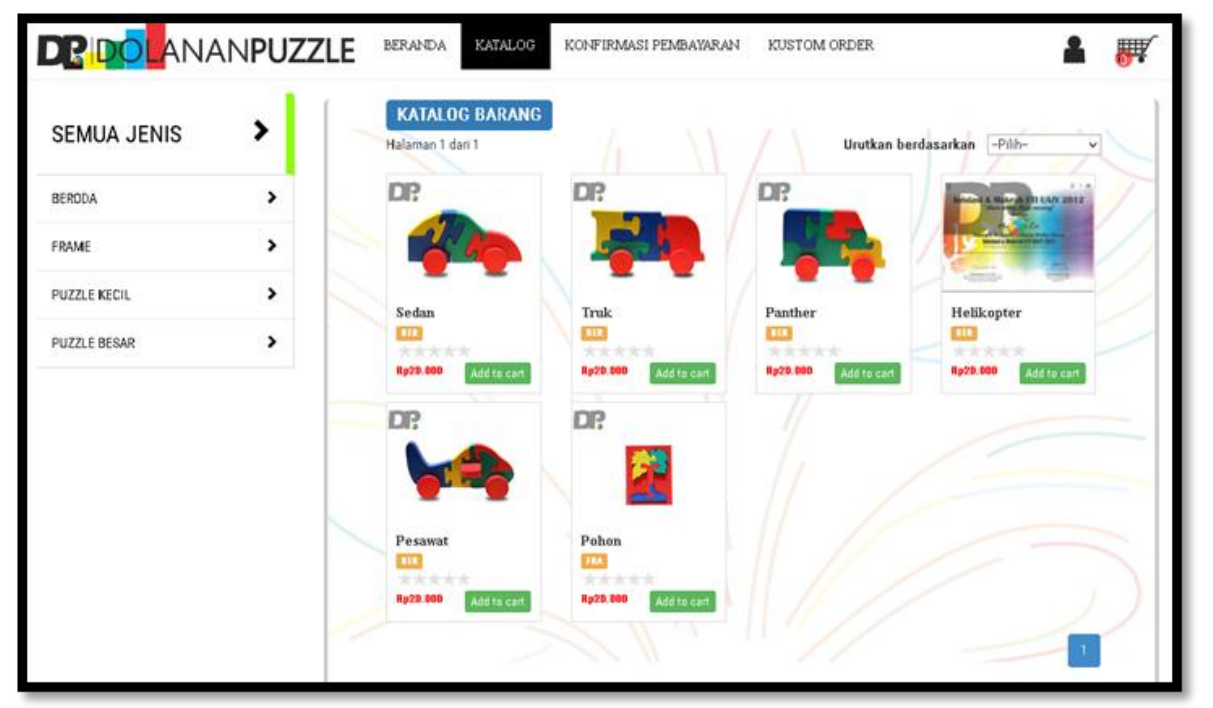

Gambar 4. Antar Muka Katalog Barang

Gambar 5 merupakan hasil implementasi untuk shopping cart. Modal dialog ini akan keluar jika user menekan simbol cart pada sebelah pojok kanan atas. Modal dialog ini akan menampilkan setiap barang yang ada di shopping cart. Pada dialog tersebut, pengguna dapat mengubah kuantitas tiap barang dengan mengganti angka pada text box "Qty". Apabila pengguna ingin menghapus, dapat dilakukan dengan menekan tulisan hapus item dari keranjang. Tombol checkout digunakan untuk menutup shopping cart dan dilanjutkan ke penutupan transaksi. Tombol "Lanjut Belanja" digunakan untuk menutup Modal Dialog.

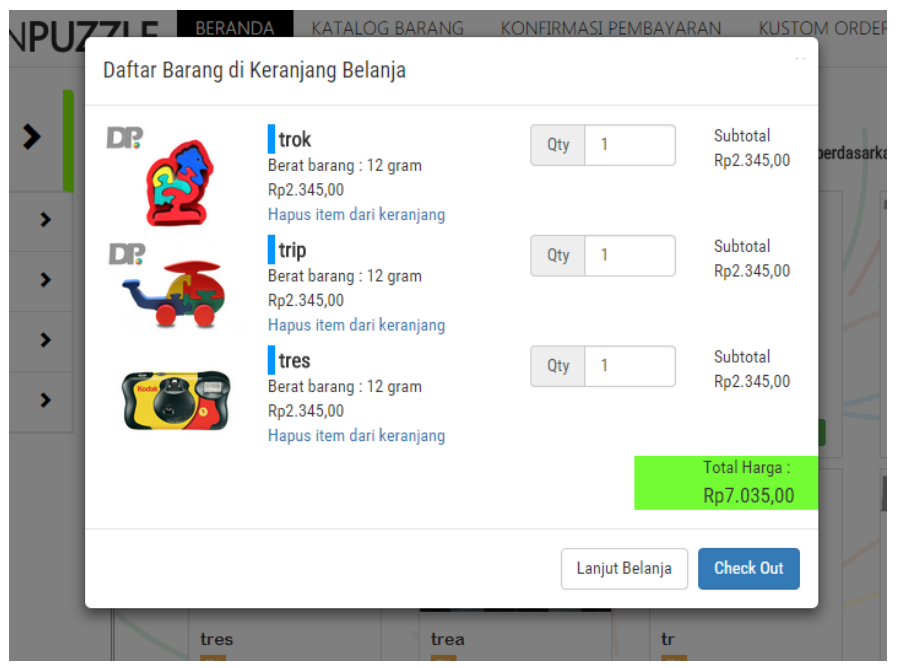

Gambar 5. Antar Muka Shopping Cart.

Apabila proses checkout sudah dilakukan, sistem akan mengirimkan e-mail konfirmasi yang berisi detil transaksi, jumlah yang harus dibayarkan seperti di tunjukkan pada Gambar 6 . Setelah konfirmasi pembayaran selesai dilakukan oleh pelanggan, maka admin akan mengupdate status transaksi dan pesanan akan segera dikerjakan. Setelah produk siap dan dikirimkan, 
maka pihak admin melalui sistem akan meng-update status transaksi dan memasukan nomer resi pengiriman ke sistem yang akan diteruskan ke pelanggan melalui e-mail seperti ditunjukan pada Gambar 7.

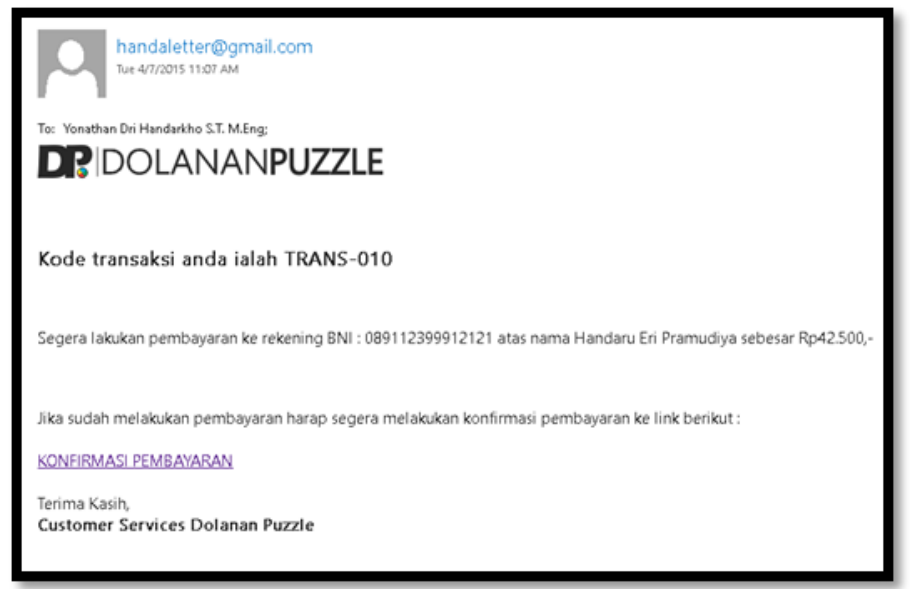

Gambar 6. Contoh e-mail konfirmasi Transaksi

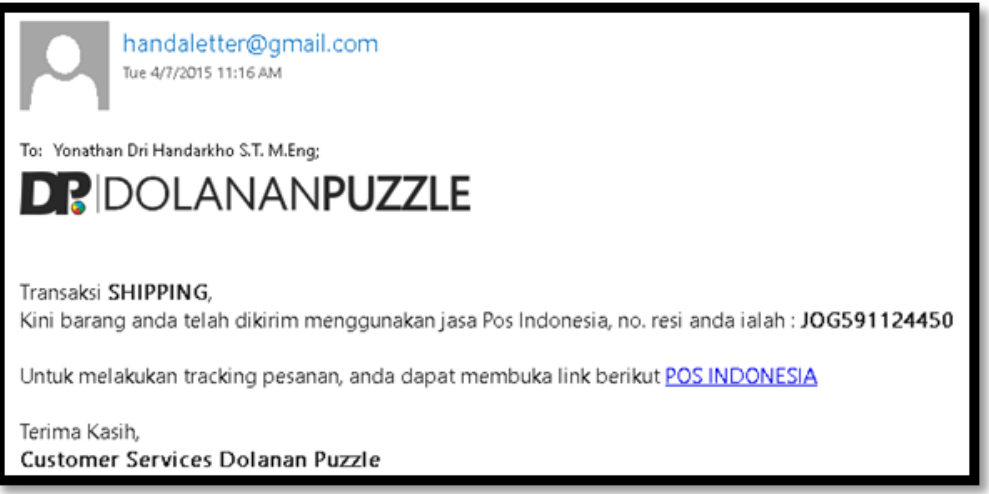

Gambar 7. Contoh e-mail konfirmasi Pengiriman Barang

Implementasi selanjutnya dari operational CRM ditunjukkan pada Gambar 8 yaitu antarmuka pengiriman e-mail barang baru kepada pelanggan potensial. Data pelanggan potensial yang ditampilkan menggunakan metode pengelompokkan pelanggan potensial. Pelanggan dikelompokkan berdasarkan ketertarikan terhadap suatu jenis kategori barang berdasarkan data transaksi yang telah dilakukan. Pelanggan yang ditampilkan adalah pelanggan yang di anggap memiliki ketertarikan terhadap barang yang baru ditambahkan berdasarkan kategori tertentu. Ketertarikan pelanggan dihitung dari history detil transaksi yang telah dilakukan pelanggan dari kategori barang tersebut. Jika pelanggan melakukan beberapa transaksi terhadap barang dari kategori tertentu, maka dapat dianggap bahwa pelanggan tersebut memiliki ketertarikan dengan kategori barang tersebut. Jadi ketika pengelola Dolanan Puzzle menambahkan barang baru dengan kategori tertentu, sistem akan mereferensikan pelanggan dengan ketertarikan terhadap kategori tersebut. Pengelola Dolanan Puzzle bisa mengirimkan $e$ mail kepada pelanggan-pelanggan potensial tersebut mengenai barang baru yang hendak ditambahkan ke dalam aplikasi. Icon bergambar e-mail digunakan sebagai tombol pemicu untuk mengirimkan e-mail kepada pelanggan yang dipilih. 


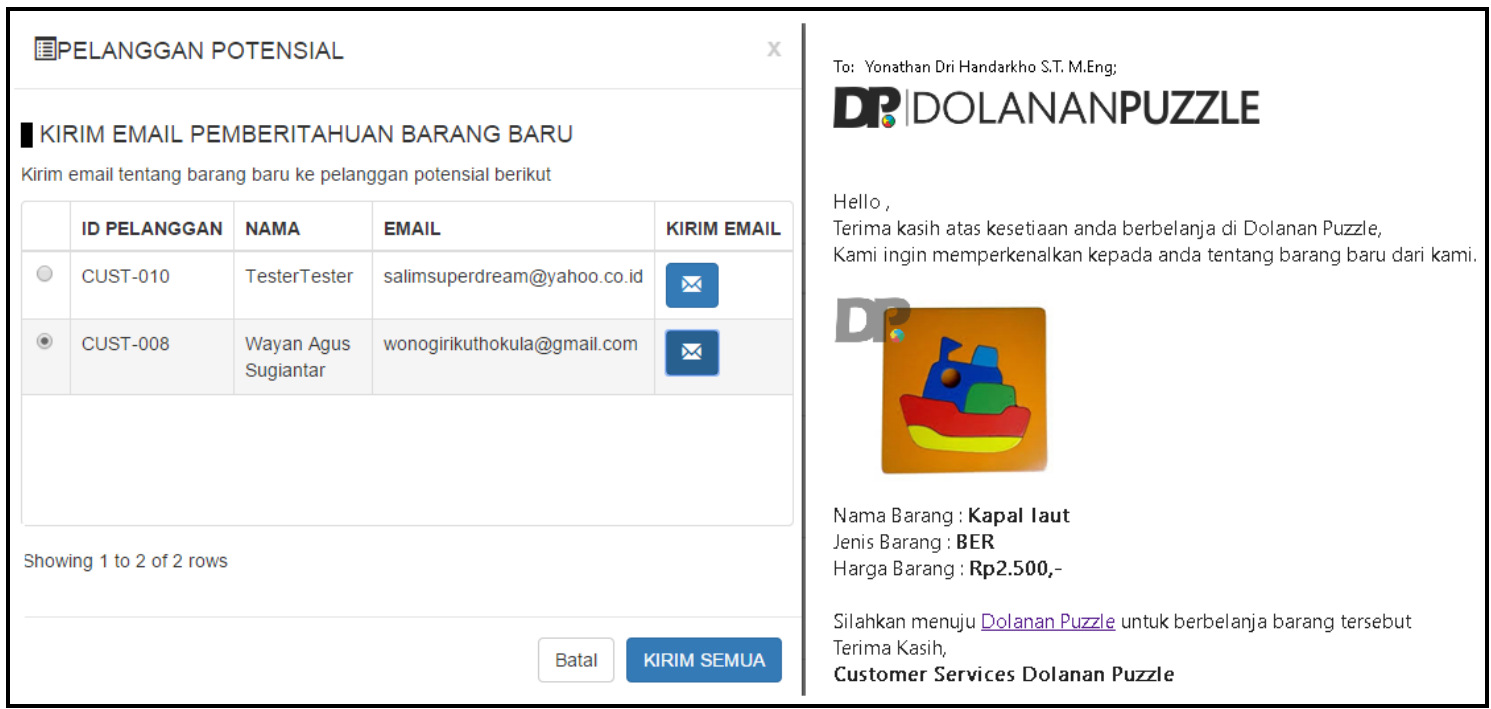

Gambar 8. Antar Muka Promosi Barang Baru Kepada Pelanggan Potensial dan Konten E-mail Promosi yang diterima pelanggan

\subsection{Implementasi Analytical CRM}

Implementasi analytical CRM ditunjukan dari implementasi algoritma Market Basket Analysis yang ditunjukan pada halaman antar muka detil barang pada Gambar 9. Informasi yang ditampilkan pada antar muka tersebut merupakan data detil dari barang seperti nama barang, jenis barang, harga barang, rating barang, dan rekomendasi barang. Proses analytical CRM ditunjukkan pada bagian rekomendasi barang. Data yang ditampilkan pada bagian tersebut diambil berdasarkan nilai yang terdapat dari tabel Market Basket Analysis. Proses perhitungan dari nilai tabel Market Basket Analysis didapatkan pada saat transaksi dari pelanggan disimpan oleh sistem. Detil prosesnya adalah setelah transaksi selesai, sistem akan menghitung afinitas antar barang dan menyimpannya ke dalam basis data. Nilai afinitas tersebut nantinya akan digunakan untuk menentukan nilai dari Market Basket Analysis (MBA) atau referensi barang bertautan berdasarkan Persamaan 1 dan Persamaan 2.

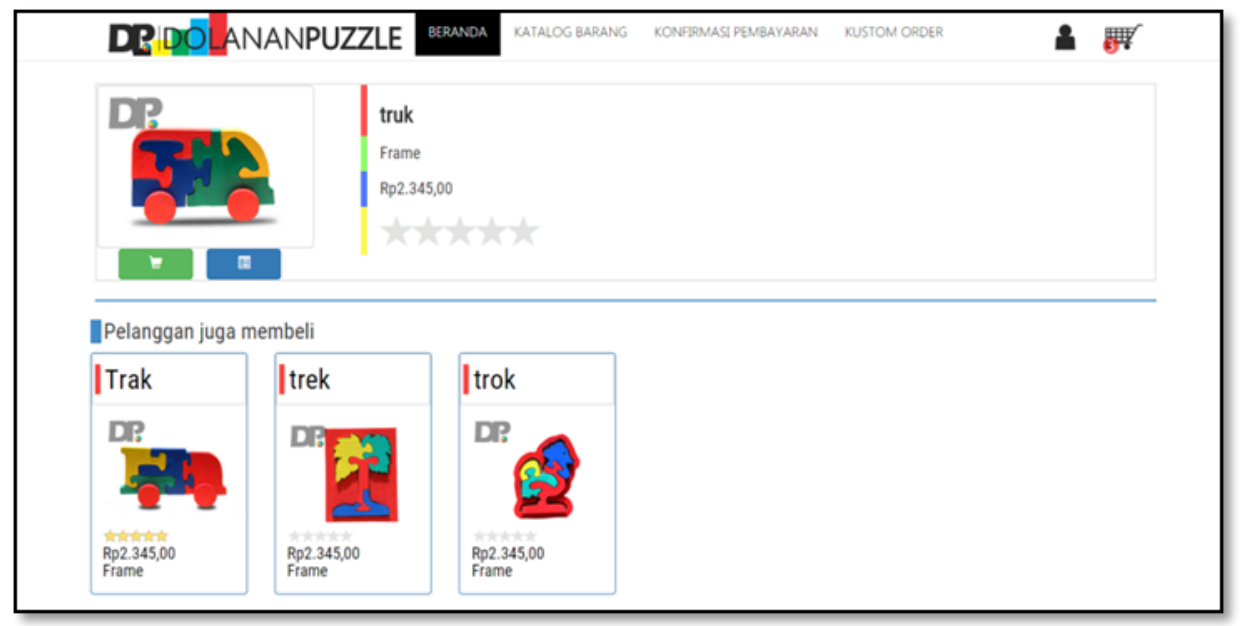

Gambar 9. Antar Muka Detil Barang

Cara perhitungan dari MBA adalah sebagai berikut: dimisalkan barang yang berada di shopping cart ialah TRUK-Puzzle, SEDAN-Puzzle, dan KUCING-Puzzle. Kemudian dari ketiga barang tersebut dihitung berapa jumlah transaksinya yang mengandung SEDAN-Puzzle, TRUK-Puzzle dan KUCING-Puzzle. Setelah diketahui jumlah transaksi yang memuat barang barang tersebut, sistem akan mengkombinasikan barang yang dibeli menjadi KUCING-Puzzle 
dan Truk-Puzzle, KUCING-Puzzle dan SEDAN-Puzzle, serta SEDAN-Puzzle dan TRUKPuzzle. Selanjutnya kombinasi barang tersebut dicari jumlah transaksi yang mengandung kombinasi barang tersebut. Market Basket Analysis dapat ditentukan dengan menghitung nilai support dan nilai confidence dari barang kombinasi tersebut. Nilai support dapat ditentukan dengan rumus support value menggunakan Persamaan 1. Sedangkan untuk nilai confidence dapat ditentukan menggunakan Persamaan 2.

Sebagai contoh, untuk menghitung nilai support dari kombinasi KUCING-Puzzle dan SEDAN-Puzzle, sistem akan mencari total transaksi yang mengandung kedua barang tersebut kemudian dibagi dengan total jumlah transaksi yang terjadi. Confidence value dapat diperoleh dengan mengambil nilai support yang diperoleh sebelumnya. Selanjutnya apabila hendak mendapatkan nilai confidence kombinasi barang KUCING-Puzzle dan SEDAN-Puzzle terhadap SEDAN-Puzzle maka nilai support tersebut dibagi dengan jumlah transaksi yang mengandung SEDAN-Puzzle. Jika dari kombinasi barang tersebut hendak dicari nilai confidence terhadap KUCING-Puzzle maka nilai support dibagi dengan jumlah transaksi yang mengandung KUCING-Puzzle. Jika digambarkan proses penghitungan secara manual, prosesnya dapat dilihat pada Gambar 10. Nantinya Nilai support dan nilai confidence yang didapat akan disimpan ke dalam basis data.

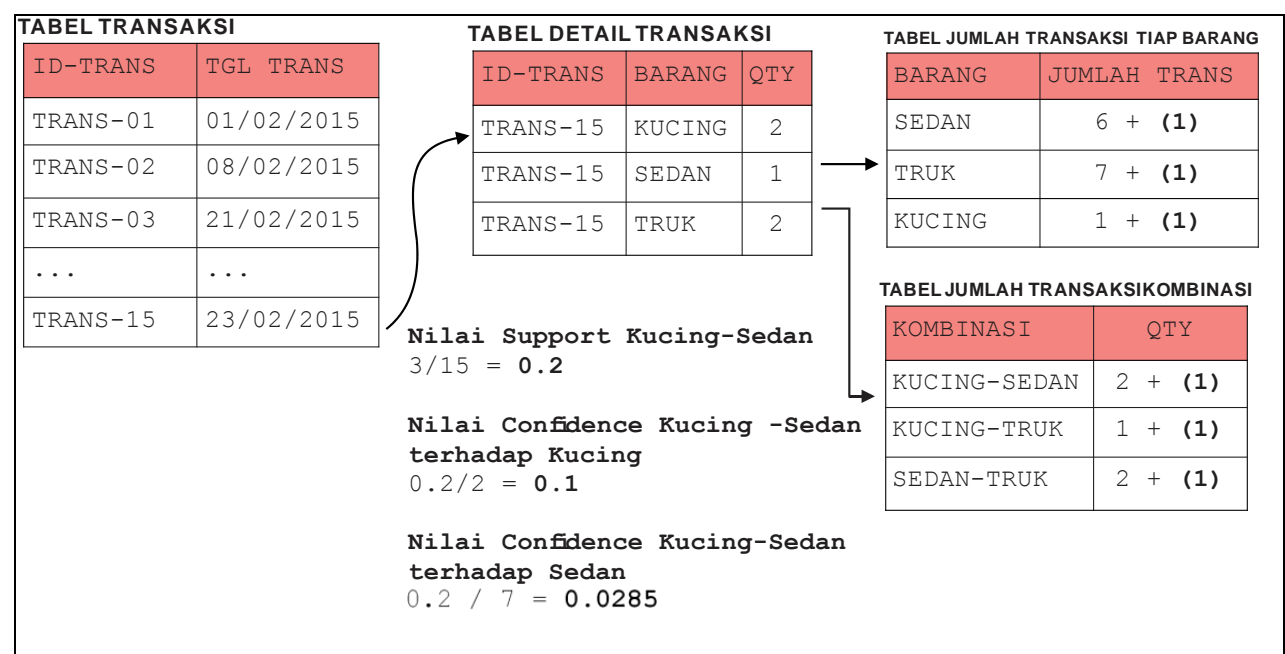

Gambar 10. Proses Mencari Nilai Support dan Confidence

Selanjutnya kembali kepada penggunaan nilai support dan confidence yang sudah didapatkan, dimisalkan sistem ingin menampilkan detail barang dari KUCING-Puzzle, maka sistem harus melihat dari tabel Market Basket Analysis dan melihat KUCING-Puzzle memiliki keterkaitan dengan barang apa saja. Sebagai contoh KUCING-Puzzle memiliki keterkaitan dengan SEDAN-Puzzle dan TRUK-Puzzle, maka sistem akan mencari dari kedua keterkaitan tersebut yaitu nilai confidence dan nilai support nya. Sistem akan mengambil barang terkait tersebut untuk ditampilkan dalam referensi barang jika memiliki nilai support lebih dari 0.5 dan nilai confidence lebih dari 0.7. Penulis menetapkan ambang batas nilai support dan confidence sebesar itu, dikarenakan nilai support digunakan untuk menentukan seberapa sering kombinasi kedua barang tersebut terjadi dan nilai confidence digunakan untuk menetukan seberapa terpercayanya kombinasi kedua barang terjadi ketika barang utama dibeli maka barang pendamping juga akan dibeli. Jika barang yang akan ditampilkan detailnya tidak tersedia di dalam tabel Market Basket Analysis, maka sistem akan menampilkan barang dengan kategori yang sama dengan detil barang yang ditampilkan dan memiliki jumlah penjualan yang tinggi.

Implementasi selanjutnya dari bagian analitycal CRM pada e-commerce ini adalah laporan rangkuman transaksi dan pengelolaan komentar dari pelanggan terhadap produk Dolanan Puzzle yang bisa diakses oleh administrator dari website ini yaitu dari pihak Dolanan Puzzle seperti ditunjukan pada Gambar11 dan Gambar 12. Pada bagian ini, pengguna bisa 
mendapatkan laporan rangkuman transaksi dalam kurun periode tertentu berdasarkan tanggal yang diinputkan oleh pengguna. Terdapat dua jenis rangkuman laporan, yang pertama adalah laporan transaksi secara umum dan yang kedua adalah laporan transaksi secara detil untuk setiap transaksi yang masuk. Sedangkan untuk pengelolaan komentar memungkinkan pihak administrator untuk melihat komentar terhadap produk yang sudah dibeli oleh pelanggan. Diharapkan melalui kedua fitur tersebut, dapat membantu pihak Dolanan Puzzle untuk mengevaluasi setiap produk yang dimilikinya baik dari sisi penjualan atau dari sisi evaluasi dari pelanggan.

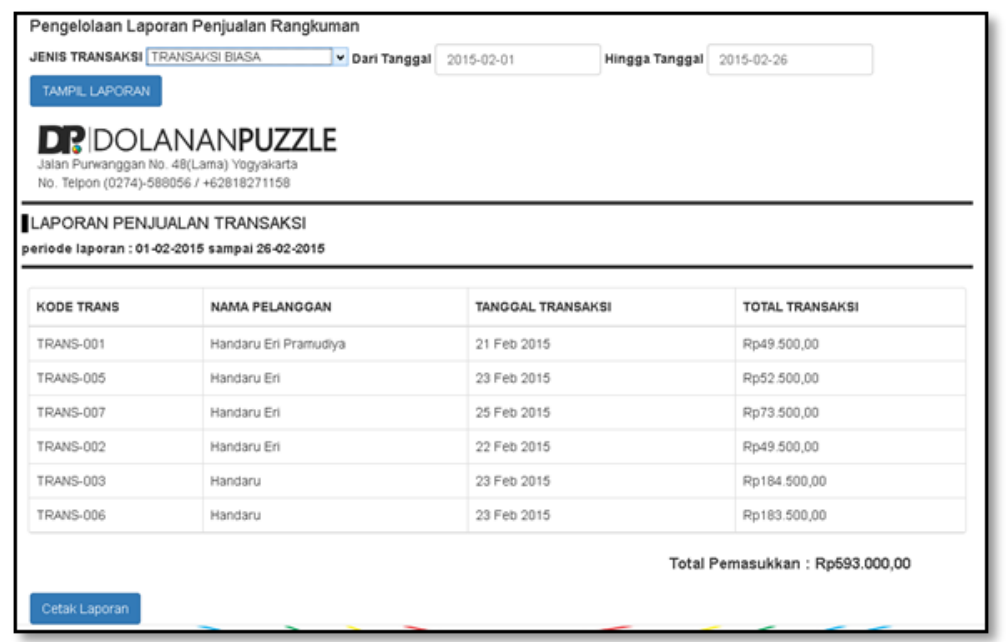

Gambar 11. Laporan Rangkuman Transaksi

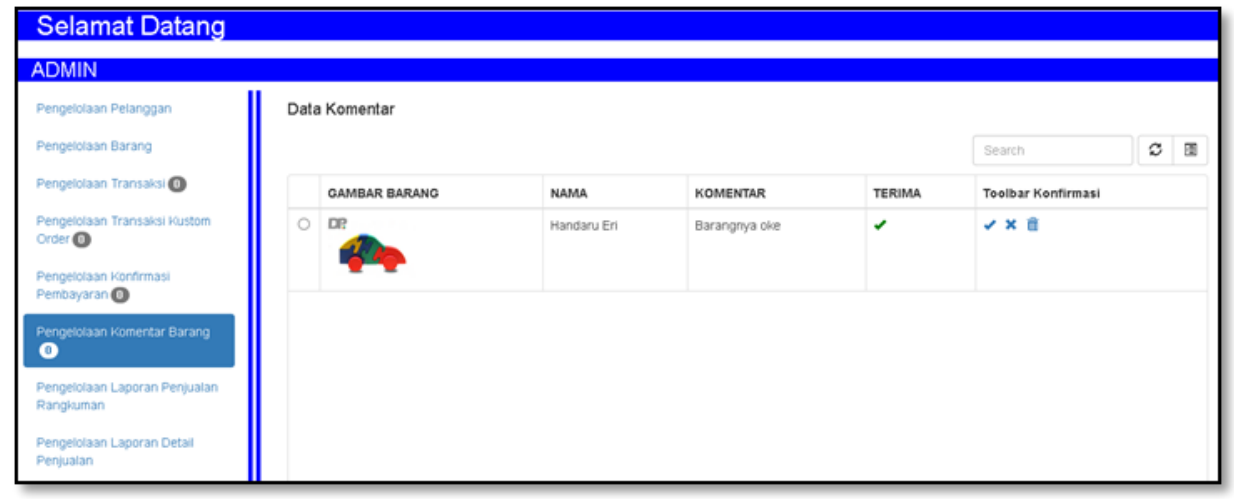

Gambar 12. Pengelolaan Komentar dari Pelanggan

\subsection{Pengujian Sistem}

Terdapat dua macam pengujian dari aplikasi EDOPLUZ yang diberikan kepada responden yaitu pengujian antarmuka dan fasilitas panel admin serta pengujian antarmuka dan fasilitas $E$ Commerce Dolanan Puzzle.

\subsubsection{Pengujian Antarmuka dan Fasilitas Situs Web Administrasi}

Pada pengujian ini, responden yang diambil sebagai objek pengujian adalah pemilik Dolanan Puzzle. Pengujian ini digunakan untuk menguji apakah antar muka dan interaksi dari proses pengelolaan data administrator seperti pengelolaan barang, pengelolaan pelanggan, pengelolaan laporan, dan pengelolaan transaksi berjalan sesuai dengan kebutuhan dan terorganisir dengan baik. Detil dari pengujian pada tahapan ini ditunjukkan pada Tabel 1 .

Rekapitulasi data yang diperoleh dari setiap pernyataan pengujian di Tabel 1 adalah sebagai berikut: (a) Pernyataan 1: Pemilik Dolanan Puzzle menjawab setuju. (b) Pernyataan 2: Pemilik Dolanan Puzzle menjawab setuju. (c)Pernyataan 3: Pemilik Dolanan Puzzle menjawab 
setuju. Dari hasil tersebut maka bisa disimpulkan bahwa pengguna aplikasi web EDOPLUZ dari sisi admin berjalan sesuai dengan kebutuhan dan terorganisir dengan baik.

Tabel 1. Tabel Pengujian Web Administrasi

\begin{tabular}{|c|c|c|c|c|c|}
\hline \multirow[t]{2}{*}{ No } & \multirow[t]{2}{*}{ PERTANYAAN } & \multicolumn{4}{|c|}{ PILIHAN JAWABAN } \\
\hline & & SS & $\mathbf{S}$ & $\mathbf{K S}$ & TS \\
\hline 1 & Antarmuka $w e b$ rapi dan enak dilihat & - & 1 & - & - \\
\hline 2 & $\begin{array}{l}\text { Pengelolaan data transaksional seperti pengelolaan barang dan data transaksional mudah } \\
\text { dipahami }\end{array}$ & - & 1 & - & - \\
\hline 3 & Secara umum Anda merasa nyaman menggunakan sistem web ini & - & 1 & - & - \\
\hline 4 & Secara umum panel Admin membantu proses transaksional Dolanan Puzzle & - & 1 & - & - \\
\hline
\end{tabular}

\subsubsection{Pengujian Antarmuka dan Fasilitas Aplikasi E-Commerce Dolanan Puzzle}

Pada pengujian ini, responden bertindak sebagai pelanggan dari Dolanan Puzzle dan diminta menguji aplikasi EDOPLUZ. Pengujian sistem dilakukan terhadap 31 responden dengan spesifikasi usia antara 20 sampai 30 tahun dengan latar belakang pekerjaan yang beragam. Tujuan dari pengujian ini adalah untuk mengukur bahwa antarmuka dan interaksi dari aplikasi membantu pengguna untuk bisa mendapatkan informasi dan melakukan transaksi dengan baik dan terorganisir.

Tabel 2. Tabel Pengujian Antarmuka dan Fasilitas Aplikasi E-Commerce Dolanan Puzzle

\begin{tabular}{|c|c|c|c|c|c|}
\hline \multirow[t]{2}{*}{ NO } & \multirow[t]{2}{*}{ PERTANYAAN } & \multicolumn{4}{|c|}{ PILIHAN JAWABAN } \\
\hline & & SS & $\mathbf{S}$ & KS & TS \\
\hline 1 & Tampilan antarmuka aplikasi & 12 & 21 & 1 & 0 \\
\hline 2 & $\begin{array}{l}\text { Adanya aplikasi E-Commerce Dolanan Puzzle mempermudah Anda menjangkau Dolanan } \\
\text { Puzzle }\end{array}$ & 13 & 20 & 1 & 0 \\
\hline 3 & Adanya referensi barang mempermudah anda untuk mencari barang lain & 10 & 21 & 3 & 0 \\
\hline 4 & $\begin{array}{l}\text { Adanya e-mail pemberitahuan tentang transaksi anda mempermudah anda untuk } \\
\text { mengetahui transaksi anda }\end{array}$ & 15 & 18 & 1 & 0 \\
\hline 6 & Secara umum anda merasa nyaman menggunakan E-Commerce Dolanan Puzzle ini & 9 & 24 & 1 & 0 \\
\hline
\end{tabular}

Rekapitulasi data yang diperoleh dari setiap peryataan di Tabel 2 adalah sebagai berikut: (a) Pernyataan 1: Sebanyak 36\% responden menyatakan sangat setuju, 61\% responden menyatakan setuju, dan hanya $3 \%$ responden menyatakan kurang setuju pada pernyataan 1 . (b) Pernyataan 2: Sebanyak 39\% responden menyatakan sangat setuju, 58\% menyatakan setuju, dan hanya 3\% dari responden menyatakan kurang setuju pada pernyataan 2. (c) Pernyataan 3: Sebanyak 30\% responden menyatakan sangat setuju, 61\% menyatakan setuju, dan $9 \%$ dari responden menyatakan kurang setuju pada pernyataan 3. (d) Pernyataan 4: Sebanyak $45 \%$ responden menyatakan sangat setuju, 52\% menyatakan setuju, dan 3\% dari responden menyatakan kurang setuju pada pernyataan 4. (e) Pernyataan 5: Sebanyak 52\% responden menyatakan sangat setuju, 39\% menyatakan setuju, dan $9 \%$ dari responden menyatakan kurang setuju pada pernyataan 5. (f) Pernyataan 6: Sebanyak 27\% responden menyatakan sangat setuju, $70 \%$ responden menyatakan setuju, dan 3\% dari responden menyatakan kurang setuju pada pernyataan 6. Dari hasil tahapan pengujian ini maka dapat disimpulkan hampir sebagian besar responden merasa nyaman untuk melakukan transaksi dan merasa terbantu dengan adanya fasilitas $e$-mail notifikasi transaksi dan adanya referensi barang yang merupakan perwujudan dari konsep CRM pada aplikasi EDOPLUZ ini.

\section{Kesimpulan}

Berdasarkan pembahasan sebelumnya, maka dapat ditarik kesimpulan dari penelitian ini sebagai berikut: 1) E-Commerce Dolanan Puzzle berhasil dibangun dan mampu menangani proses penjualan, pemasaran, dan pemesanan barang dari Dolanan Puzzle. 2) Pengimplementasian analytical dan operational CRM di wujudkan dalam bentuk: rekomendasi produk yang sering dibeli oleh pelanggan lain ketika membeli sebuah barang dengan menggunakan metode Market Basket Analysis, pengelompokkan pelanggan potensial yang 
digunakan sebagai sasaran pengiriman promosi barang baru melalui e-mail dan laporan rangkuman transaksi dari Dolanan Puzzle.

Untuk pengembangan selanjutnya, terutama untuk meningkatkan peranan CRM, sangat dimungkinkan untuk dilakukan penambahan fitur yang bisa meningkatkan relasi antara Dolanan Puzzle dengan pelanggannya seperti melalui penggunaan teknologi sms gateway untuk memberikan notifikasi kepada pelanggan terkait dengan proses pemesanan barang.

\section{Referensi}

Garcia, I., Pacheco, C., Martinez, A. 2012. Identifying Critical Success Factors for Adopting CRM in Small: A Framework for Small and Medium Enterprises. Software Engineering Research, Management and Applications 2012, Studies in Computational Intelligence Volume 430, 2012, pp 1-15

Ghobakhloo, Morteza; Tang Sai Hong, Mohammad Sadegh Sabouri, dan Norzima Zulkifli. 2012. Strategies for Successful Information Technology Adoption in Small and Medium-sized Enterprises. Information, 3(1), 36-67.

Govindaraju, R.2011. E-commerce Adoption by Indonesian Small, Medium, and Micro Enterprises (SMMEs): Analysis of goals and barriers. Communication Software and Networks (ICCSN), 2011 IEEE 3rd International Conference

Hashim, R. 2012. Adoption of enterprise information system (EIS) in Malaysian small and medium enterprises (SMEs). Business, Engineering and Industrial Applications (ISBEIA), 2012 IEEE Symposium: 425 - 430.

McMaster, James; Kato, Maki; Khan, Natasha. 2004. Economic Impact of E-commerce on Small Tourism Enterprises. Fiji: ICT Capacity Building at USP Project, the University of the South Pacific.

Mishra, Alok., Mishra, Deepti.2009. Customer Relationship Management: Implementation Process Perspective. Acta Polytechnica Hungarica, Vol. 6, No. 4, 2009.

Nurcahyo, Gunadi W.2013.Penerapan Data Mining dengan Algoritma Apriori untuk Mendukung Strategi Promosi Pendidikan. Jurnal Ilmiah Community Research Information Technology.Vol. 1 No. 1 March 2013

Poorangi, Mehdi M., Khin, Edward W.S., Nikoonejad, Shohreh dan Kardevani, Arash. 2013. Ecommerce adoption in Malaysian Small and Medium Enterprises Practitioner Firms: A revisit on Rogers' model. Annals of the Brazilian Academy of Sciences (2013) 85(4):1593-1604

Stale, G. \& Majors, I. 2010. Applying knowledge Management methods and enterprise modelling solution to the IT "ecosystem" for continuing education in SME's. Dubai: Digital Ecosystems and Technologies (DEST), 2010 4th IEEE International Conference.

Sudjana, D. 2004. Pendidikan Nonformal (Nonformal Education) Wawasan, Sejarah Perkembangan, filsafat, Teori Pendukung, Asas. Bandung: Falah Production.

Svetina, Marko., Zupančič, Jože.2005. How to Increase Sales in Retail with Market Basket Analysis. System Integration, 418-428.

Tedjasaputra, Mayke S.2001. Bermain Mainan dan Permainan untuk Pendidikan Anak Usia Dini. Jakarta: Grasindo. 